\title{
Pre, middle or Post pandemic: Routine vaccination is essential!
}

\author{
Carlos E. Medina-De la Garza ${ }^{1,2 *}$ and M. de los Ángeles Castro-Corona ${ }^{1,2}$ \\ ${ }^{1}$ Immunology Service, School of Medicine and "Dr. Jose E. Gonzalez", University Hospital; ${ }^{2}$ Center for Research and Development in Health Sciences \\ (CIDICS). Universidad Autónoma de Nuevo León, Monterrey, Nuevo Leon, Mexico
}

"...You have erased from the calendar of human afflictions one of its greatest. Yours is the comfortable reflection that mankind can never forget that you have lived. Future nations will know by history only that the loathsome smallpox has existed and by you has been extirpated..."

(letter, Thomas Jefferson to Edward Jenner, 1806)

This magnificent letter from Thomas Jefferson to Edward Jenner on the efficacy of his pox vaccine shows the clear vision of a leader understanding in his time what could happen in the future. Almost 215 years later, 2020 in the calendar of human afflictions, we find ourselves amidst the great concern, fear, and disinformation created by the pandemic of coronavirus disease (COVID-19) caused by severe acute respiratory syndrome coronavirus 2 (SARS CoV2). With a basic reproductive number $\left(R_{0}\right)$ of 2.5 and a global estimated case fatality rate of around $1 \%$ (adjusted for asymptomatic and mild illness) ${ }^{1}$, this rapidly spreading infection has shaken our world, as we knew it, medically, socially, and economically. Efforts to date to achieve a working vaccine have been unprecedented: there are to date more than 165 prospects of vaccine, some of which have already entered testing in humans and whose development can be followed elsewhere ${ }^{2}$.

This is not about COVID-19 vaccines, however, instead about the vaccines, we use already in our actual schemes. As physicians, health care workers or health administrators, we cannot afford to lose control of best vaccination practices because of the pandemics. We have to enforce and keep health system policies and recommendations on vaccination. However, beyond difficulties to keep vaccination levels in difficult times, we should remember the World Health Organization (WHO) listed in 2019 vaccination hesitancy as a health threat of major concern. In addition, current times are in for the continued attack on vaccines and vaccination. We must face it and properly respond to, and our commitment should start at the individual level: every general practitioner, specialist, resident, nurse, health care worker, or student should consider this his/her task. Let no one tell you otherwise: vaccines and vaccination do save lives, as succinctly shown by Orenstein and Ahmed in a bright editorial everyone should read ${ }^{3}$. As they correctly state, is vaccination which saves lives, not just the vaccine itself. Health care workers need more than ever before to be knowledgeable about vaccines and follow information from accurate sources, that is, the WHO and Centers for Disease Control and Prevention to be able to counter arguments against vaccination ${ }^{4}$. Other institutions also provide trustful and concise information, such as the Immunization Action Coalition (https.//www.immunize.org) and the College of Physicians of Philadelphia, (https:// historyofvaccines.org) both great teaching resources as well. In a purposeful manner, we do not focus on those who do not believe in vaccines, but instead in further empowering those health care workers who use and know about vaccines, know their efficacy and their real risk/

\section{Correspondence:}

${ }^{*}$ Carlos E. Medina-De la Garza

E-mail: carlos.medina@uanl.mx
Available online: $30-10-2020$

Date of reception: 30-07-2020

Date of acceptance: 07-08-2020 DOI: 10.24875/RMU.M20000047
Medicina Universitaria. 2020;22(3):93-94 www.medicinauniversitaria.org

1665-5796/@ 2020 Universidad Autónoma de Nuevo León. Published by Permanyer. This is an open access article under the CC BY-NC-ND license (http://creativecommons.org/licenses/by-nc-nd/4.0/). 
benefit ratio. Some of them may nevertheless doubt and hesitate in face of pressure by social media and misleading information, and so unwillingly create vaccine disregard, and disbelief in peers and patients altogether. Improving knowledge on vaccines and increasing the capacity to communicate trustworthy information to concerned parents or hesitant individuals is one desirable approach ${ }^{3}$. We as health-care providers are obligated to keep us updated about new vaccines but above all about vaccine schemes, we are using right here, right now, and thus be able to generate trust among patients and coworkers by rejecting rumors, fake news, and misinformation ${ }^{4}$. No doubt, we should remain vigilant on adequate development and safety of vaccines. Nevertheless, we must keep on using vaccines as the powerful tool of public health they are and help build trust around their use. In the uncertain times of pandemics, let's not forsake the advancements we have done in many fields to decrease the burden of infectious disease, were vaccination play an essential role, and whose acceptance by the public is necessary to maintain herd immunity and avoid outbreaks of preventable diseases ${ }^{4,5}$. We shall respect and be able to make the most of the valuable lessons infectious disease give us every passing day. Indeed, the past lessons show that responsibility of avoiding reemerging infections and outbreaks of vaccine-preventable diseases is still ours.

\section{References}

1. Petersen E, Koopmans M, Unieong G, Hamer DH, Petrosillo N, Cast lli F, et al. Comparing SARS-Cov-2 with SARS and influenza pandemics. Lancet Infect Dis. 2020;20(9):e238-e244.

2. Corum J, Grady D, Wee SL, Zimmer C. New York Times Vaccine Tracker. Available from: https://www.nytimes.com/interactive/2020/science/ coronavirus-vaccine-tracker.html. [Last accessed on 2020 Jul 29].

3. Orenstein WA, Ahmed R. Simply put: vaccination save lives. Proc Natl Acad Sci U S A. 2017;114(16):4031-3.

4. Callender D. Vaccine hesitancy: more than a movement. Hum Vaccin Immunother. 2016;12:2464-8.

5. Puri N, Coomes EA, Haghbayan H, Gunarante K. Social media and vaccine hesitancy: new updates for the era of COVID-19 and globalized infectious diseases. Hum Vacc Immunother. 2020. In pres. doi: https:// doi.org/10.1080/21645515.2020.1780846 